\title{
Analisis Kadar Alkohol dalam Obat Batuk Sirup dengan Menggunakan Metode Headspace Kromatografi Gas
}

\author{
Dedy Suseno ${ }^{1}$ dan Qomariyah ${ }^{2}$ \\ ${ }^{1}$ Halal Research Center Universitas YARSI \\ 2Fakultas Kedokteran Universitas YARSI \\ dedy.suseno@yarsi.ac.id¹ dan qomariyah@yarsi.ac.id²
}

\section{ABSTRAK}

Diajukan 17 Mei 2021 Diperbaiki 11 Agutus 2021 Diterima 15 Agustus 2021

\begin{abstract}
Latar Belakang: Alkohol atau etanol merupakan salah satu bahan baku obat yang biasa digunakan sebagai bahan pelarut dalam obat batuk sirup. Penggunaan alkohol tersebut perlu dikritisi, terutama dalam penggunaan konsentrasi yang tinggi. Nilai konsentrasi alkohol yang tinggi dalam darah dapat menyebabkan gangguan penglihatan, reaksi yang melemah, gangguan koordinasi, dan kelabilan emosi. Ditemukannya kandungan alkohol dalam obat batuk herbal yang dalam kemasannya tidak mencantumkan keterangan alkohol perlu menjadi perhatian serius, khususnya bagi konsumen.

Tujuan: Menganalisis konsentrasi alkohol dalam obat batuk sirup yang dalam kemasannya tidak mencantumkan keterangan alkohol.

Metode: Empat belas sampel obat batuk sirup yang tidak menuliskan keterangan alkohol dan satu sampel obat batuk sirup yang menuliskan keterangan alkohol dalam kemasan dianalisis kandungan alkoholnya menggunakan metode headspace kromatografi gas. Konsentrasi alkohol dalam sampel didapatkan dengan memasukkan nilai persamaan regresi standar alkohol ke dalam rumus kadar residual solvent.

Hasil: Sembilan sampel terdeteksi mengandung alkohol dengan rentang konsentrasi alkohol 0,045 \% b/ b sampai $0,503 \%$ b/b dan $0,074 \% \mathrm{v} / \mathrm{v}$ sampai $1,569 \% \mathrm{v} / \mathrm{v}$.

Kesimpulan: Sembilan sampel terdeteksi mengandung alkohol dengan konsentrasi terbesar yaitu $1,569 \% \mathrm{v} / \mathrm{v}$ dan $0,503 \% \mathrm{~b} / \mathrm{b}$.
\end{abstract}

Kata Kunci: Obat Batuk; Sirup; Alkohol

\section{ABSTRACT}

Background: Alcohol or ethanol is one of the raw materials of drugs commonly used as a solvent in cough syrup. The use of such alcohol needs to be criticized especially in the use of high concentrations. High alcohol concentration values in the blood can cause impaired vision, weakened reactions, impaired coordination, and emotional impairment. The finding of alcohol content in herbal cough medicines which does not include alcohol information in the packaging needs to be a serious concern, especially for consumers.

Objective: Analyzing the alcohol concentration in cough syrup which does not include alcohol description in the packaging.

Methods: Fourteen samples of cough syrup that did not include alcohol description and one sample of cough syrup that included alcohol description in the packaging were analyzed their alcohol content using the gas chromatography headspace method. The concentration of alcohol in the sample was obtained by involving the standard alcohol regression equation value into the residual solvent level formula.

Results: Nine samples were detected containing alcohol with concentration range of $0,045 \%$ w/w to $0,503 \% w /$ $w$ and $0,074 \%$ v/v to $1,569 \%$ v/v.

Conclusion: Nine samples were detected containing alcohol with the largest concentrations of $1.569 \% \mathrm{v} / \mathrm{v}$ and $0.503 \% w / w$.

Keywords: Cough Syrup; Syrup; Alcohol 


\section{PENDAHULUAN}

Alkohol atau etanol merupakan salah satu bahan baku yang banyak digunakan dalam memproduksi obat cair. Biasanya alkohol tersebut digunakan sebagai bahan pelarut dan pengawet dalam obat batuk.

Penggunaan obat batuk yang mengandung alkohol perlu mengikuti petunjuk yang telah tercantum dalam kemasan obat. Hal ini dikarenakan alkohol yang masuk ke dalam tubuh akan berpengaruh terhadap konsentrasi alkohol dalam darah. Neo et al. (2017) menyatakan bahwa nilai konsentrasi alkohol dalam darah sebesar $1,80 \mathrm{~g} / \mathrm{L}$ dapat menyebabkan gangguan penglihatan, reaksi yang melemah, gangguan koordinasi dan kelabilan emosi.

Penggunaan alkohol dalam obat batuk cair perlu diwaspadai, terutama jika digunakan oleh bayi yang baru lahir. Hal ini disebabkan karena bayi memiliki resiko yang besar terhadap keracunan akut dan kronis alkohol (Zuccotti \& Fabiano, 2011).

Amerika, melalui FDA (Food and Drugs Administration) menyatakan bahwa penggunaan konsentrasi maksimum alkohol dalam obat-obatan oral dibagi menjadi beberapa rentang usia. Pada anakanak dan dewasa di atas umur 12 tahun, batasan maksimum konsentrasi alkohol dalam obat ialah $10 \%$, sedangkan pada anak-anak di bawah usia 12 tahun dan 6 tahun, kadar konsentrasi alkohol maksimum dalam obat ialah sebesar 5\% dan $0.5 \%$ (Neo et al., 2017).

The European Medicine Agency (EMA) merekomendasikan produk obat herbal yang mengandung alkohol harus menuliskan kandungan alkoholnya dalam kemasan dengan jelas (Neo et al., 2017). Di Indonesia sendiri, penggunaan alkohol dalam obat diatur oleh Badan Pengawas Obat dan Makanan (BPOM).

Aturan penggunaan alkohol tersebut tertulis dalam Peraturan Kepala Badan Pengawas Obat dan Makanan Republik $\begin{array}{lll}\text { Indonesia } & \text { (BPOM } & \text { RI) }\end{array}$
HK.03.1.23.06.10.5166 Tahun 2010 tentang kandungan alkohol pada obat, obat tradisional, suplemen makanan, dan pangan. Merujuk pada aturan tersebut, produsen wajib mencantumkan kadar alkohol (dalam bentuk \%) pada kemasannya.

Hal yang menjadi masalah adalah apabila ditemukan produk obat batuk yang dalam kemasannya tidak mencantumkan keterangan alkohol, tetapi terdeteksi mengandung alkohol setelah diuji laboratorium. Apabila hal ini terjadi, kondisi tersebut akan membahayakan kesehatan konsumen yang mengonsumsi obat batuk tersebut.

Penelitian Neo et al. (2017) tentang obat batuk herbal di Malaysia menyatakan bahwa sampel yang diteliti mengandung alkohol dengan rentang 0,102\% - 2,576\% (v/ v) dan sampel tersebut tidak menuliskan kandungan alkohol dalam kemasaannya. Penelitian tersebut menjadi acuan untuk melihat apakah hasil penelitian tersebut bisa terjadi pula pada sampel obat batuk sirup yang umum dijumpai di Indonesia.

Tujuan penelitian ini adalah untuk menganalisis adanya kandungan alkohol dalam obat batuk sirup yang dalam kemasannya tidak mencantumkan keterangan alkohol. Manfaat penelitian ini bagi konsumen ialah informasi yang didapatkan dapat digunakan sebagai rujukan dalam memilih obat batuk sirup, sedangkan bagi BPOM. Hasil penelitian ini akan menjadi informasi penting jika sampel yang digunakan ternyata mengandung alkohol.

\section{METODE}

Metode penelitian analisis alkohol dalam obat batuk sirup mengacu pada United States Pharmacopeia (2016). Alkohol dalam sampel dianalisis dengan menggunakan alat headspace kromatografi gas yang dilengkapi dengan detektor FID (Flame ionization detector).

Sampel yang digunakan adalah 14 obat batuk sirup yang dalam kemasannya 
Analisis Kadar Alkohol dalam Obat Batuk Sirup dengan...

tidak mencantumkan keterangan alkohol dan 1 sampel obat batuk sirup yang dalam kemasannya mencantumkan keterangan alkohol. Semua sampel merupakan obat batuk sirup yang umum digunakan oleh masyarakat dan dapat dibeli pada apotek maupun toko obat.

Adanya kandungan alkohol dalam sampel terlihat dari adanya puncak pada rentang waktu tertentu dalam kromatogram kromatografi gas. Analisis data kadar alkohol atau kadar residual solven dalam sampel didapat dengan menggunakan kurva kalibrasi standar alkohol pada persamaan garis $\mathrm{Y}=\mathrm{bx}+\mathrm{a}$ yang dimasukkan ke dalam rumus berikut.

kadar residual solvent $\left(\frac{m g}{K g}\right)=\frac{\frac{\text { Luas area spl }-a}{b}}{W_{s p l}}$

Keterangan:

$\mathrm{a}=$ Intercept dari kurva kalibrasi standar alcohol;

$\mathrm{b}=$ slope dari kurva kalibrasi standar alkohol; $\mathrm{W}_{\text {spl }}=$ bobot penimbangan sampel (g).

\section{Kondisi Pengukuran Instrumen}

Penelitian ini untuk analisis alkohol dalam sampel dibagi menjadi 2 tahapan. Tahap pertama adalah pemisahan senyawa yang mudah menguap dalam sampel dengan menggunakan metode headspace dan tahap kedua adalah analisis kandungan alkohol dalam sampel dengan menggunakan metode kromatografi pada alat kromatografi gas.

Sebelum digunakan untuk analisis, headspace terlebih dahulu didiamkan selama 15 menit. Pengaturan headspace yang perlu dilakukan, yaitu needle temperature $\left(85^{\circ} \mathrm{C}\right)$, transfer line temperature $\left(100^{\circ} \mathrm{C}\right)$, oven $\left(85^{\circ} \mathrm{C}\right)$, pressurize $(1 \mathrm{menit})$, injection time (0,04 menit), withdraw (0.5 menit), thermostat/oven time (40 menit), dan GC cycle time (24 menit).

Pada metode kromatografi digunakan alat kromatografi gas (GC), dan gas nitogen digunakan sebagai gas pembawa. Kolom kromatografi gas yang digunakan adalah capillary column DB-624 dengan FID yang digunakan sebagai detektor. Penyesuaian kondisi alat dilakukan pada Inlet Injection mode = Split 2,5:1, Injection temperature $\left(140^{\circ} \mathrm{C}\right)$, Constant velocity $(25$ $\mathrm{cm} /$ detik), dan Initial Temperature pada $40^{\circ} \mathrm{C}$, ditahan selama 5 menit.

\section{Preparasi Sampel}

Sampel obat batuk sirup sebanyak 1 gram atau sebanyak $1 \mathrm{~mL}$ ditempatkan dalam vial headspace. Sebanyak $4 \mathrm{~mL}$ DMF $50 \%$ ditambahkan ke dalam vial headspace lalu kunci dengan crimper $20 \mathrm{~mm}$. Larutan ini digoyang- goyangkan perlahan namun jangan sampai larutan kontak dengan tutup vial. Jika sudah tercampur sempurna, sampel ditempatkan dalam headspace yang kemudian akan diinjeksikan ke dalam kromatografi gas.

\section{Pembuatan Kurva Standar Alkohol}

Pembuatan kurva standar alkohol dilakukan dengan mengencerkan standar alkohol 99,9\% hingga didapatkan konsentrasi alkohol sebesar 77638,78 mg/ L. Dari larutan tersebut dipipet sebanyak 0,01 mL, 0,02 mL, 0,05 mL, 0,1 mL, 0,2 mL, 0,3 mL, 0,5 mL, 0,75 mL dan $1 \mathrm{~mL}$. Kemudian, masing-masing ditempatkan dalam labu $10 \mathrm{~mL}$ dan dicukupkan volumenya.

Larutan yang telah siap selanjutnya diinjeksikan ke dalam kromatografi gas. Data yang didapatkan berupa grafik luas area $(\mathrm{Y})$ terhadap konsentrasi alkohol (x) dalam $\mathrm{mg} / \mathrm{L}$ dan memiliki persamaan $\mathrm{Y}=$ $\mathrm{bx}+\mathrm{a}$. Nilai batas deteksi alat atau Limit of Detection (LoD) dan batas kuantitasi alat atau Limit of Quantification (LoQ) didapatkan dari data pengulangan hasil pembacaan kurva standar alkohol dan analisis datanya dapat merujuk kepada Riyanto (2014). 
Analisis Kadar Alkohol dalam Obat Batuk Sirup dengan...

HASIL DAN PEMBAHASAN

\section{Kurva Standar Alkohol}

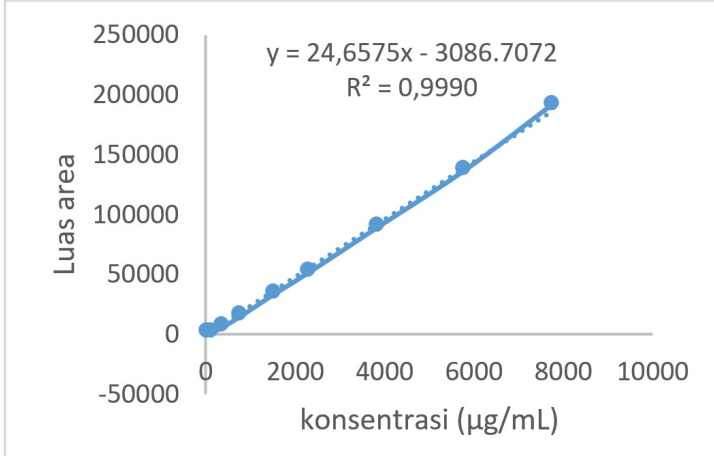

Gambar 1. Kurva standar alkohol

Gambar 1 tersebut merupakan kurva standar alkohol yang menggambarkan konsentrasi alkohol $(\mathrm{x})$ terhadap luas area (y) dalam kromatogram. Semakin tinggi konsentrasi alkohol maka semakin luas pula luas area yang dihasilkan.

Persamaan $\mathrm{y}=24,6575 \mathrm{x}-3086,7072$ menyatakan bahwa kenaikan 1 nilai $\mathrm{x}$ maka akan menyebabkan bertambahnya nilai y sebesar 24,6575. Nilai koefisien determinasi (R2) yang mendekati 1 menggambarkan bahwa analisis standar alkohol dilakukan secara teliti sehingga memberikan respons yang linier pada peningkatan nilai konsentrasi alkohol terhadap peningkatan luas area.

\section{Hasil Analisis Alkohol dalam Sampel}

Tabel 1 menunjukkan hasil analisis alkohol dalam sampel obat batuk sirup. Sebanyak 9 sampel yang tidak menuliskan keterangan alkohol dalam kemasaanya terdeteksi mengandung alkohol dengan konsentrasi yang bervariasi. Satu sampel yang dalam kemasaannya menuliskan keterangan alkohol kurang dari 1\% tidak terdeteksi mengandung alkohol setelah dianalisis menggunakan metode headspace kromatografi gas.

Tabel 1. Data konsentrasi kandungan alkohol dalam sampel

\begin{tabular}{cccc}
\hline No & Kode Sampel & Konsentrasi alkohol & Persentase konsentrasi alkohol \\
\hline 1. & $\mathrm{~A}$ & $3208,7 \mathrm{mg} / \mathrm{L}$ & 0,411 \\
2. & $\mathrm{~B}$ & Tidak terdeteksi & Tidak terdeteksi \\
3. & $\mathrm{C}$ & Tidak terdeteksi & Tidak terdeteksi \\
4. & $\mathrm{D}$ & $12234,48 \mathrm{mg} / \mathrm{L}$ & 1,569 \\
5. & $\mathrm{E}$ & $759,84 \mathrm{mg} / \mathrm{L}$ & 0,098 \\
6. & $\mathrm{~F}$ & $1140,76 \mathrm{mg} / \mathrm{Kg}$ & 0,114 \\
7. & $\mathrm{G}$ & Tidak terdeteksi & Tidak terdeteksi \\
8. & $\mathrm{H}$ & $575,48 \mathrm{mg} / \mathrm{L}$ & 0,074 \\
9. & $\mathrm{I}$ & Tidak terdeteksi & Tidak terdeteksi \\
10. & $\mathrm{~J}^{*}$ & Tidak terdeteksi & Tidak terdeteksi \\
11. & $\mathrm{~K}$ & $447,91 \mathrm{mg} / \mathrm{kg}$ & 0,045 \\
12. & $\mathrm{~L}$ & $3087,71 \mathrm{mg} / \mathrm{L}$ & 0,396 \\
13. & $\mathrm{M}$ & $5025,24 \mathrm{mg} / \mathrm{Kg}$ & 0,503 \\
14. & $\mathrm{~N}$ & Tidak terdeteksi & Tidak terdeteksi \\
15. & $\mathrm{O}$ & $2672,99 \mathrm{mg} / \mathrm{Kg}$ & 0,267 \\
\hline Keterangan & $*$ memiliki logo Halal MUI &
\end{tabular}

\section{Linearitas Kurva Standar Alkohol}

Linieritas adalah kemampuan metode analisis untuk memberikan respons proporsional terhadap konsentrasi analit dalam sampel. Linieritas metode dapat menggambarkan ketelitian pengerjaan analisis suatu metode yang ditunjukkan oleh nilai koefisien determinasi (R2) dengan syarat nilai R2 > 0,997 (Riyanto, 2014).
Alat kromatografi gas akan mempunyai linieritas yang tinggi bila menghasilkan data nilai korelasi (r) yang mendekati 1. Hal ini juga menggambarkan bahwa detektor yang digunakan memberikan respons yang linier antara luas puncak/area dan konsentrasi alkohol dalam sampel (Astuti, et al., 2018). Hasil penelitian menunjukkan bahwa kurva standar alkohol memiliki persamaan $\mathrm{Y}=$ 
24,6575X - 3086,7072 dengan R2 sebesar 0,999 dan $\mathrm{r}=0,9995$.

Limit deteksi (LoD) adalah konsentrasi analit terendah yang dapat dideteksi dan diidentifikasi dengan mengingat tingkat kepastian. Limit kuantitasi (LoQ) adalah konsentrasi terendah analit dalam sampel yang dapat ditentukan dengan presisi dan akurasi yang dapat diterima dibawah kondisi yang disepakati (Riyanto, 2014).

Alat kromatografi gas yang digunakan memiliki nilai batas deteksi (LoD) alkohol sebesar 2,8 mg/L atau 3,59 x $10-4 \%$ v/v. Jika sampel yang diuji memiliki konsentrasi alkohol di bawah LoD-nya, kandungan alkoholnya tak akan terdeteksi.

\section{Konsentrasi Alkohol dalam Sampel Obat Batuk Sirup}

Peraturan Kepala Badan Pengawas Obat dan Makanan Republik Indonesia (BPOM RI) No HK.03.1.23.06.10.5166 Tahun 2010 tentang kandungan alkohol pada obat, obat tradisional, suplemen makanan, dan pangan menyatakan bahwa produsen wajib mencantumkan kadar alkohol pada kemasannya. Kadar alkohol dituliskan dalam kemasan dalam bentuk persen (\%).

Jika ditemukan suatu obat, obat tradisional, suplemen makanan, dan pangan yang mengandung alkohol pada produknya, tetapi produsen dengan sengaja tidak mencantumkan kadar alkohol pada label kemasan, berarti produsen telah menyalahi aturan. Selain itu, produsen juga telah melanggar Undang-Undang Republik Indonesia Nomor 8 Tahun 1999 tentang perlindungan konsumen, yaitu hak atas informasi yang benar, jelas, dan jujur mengenai kondisi dan jaminan barang dan atau jasa.

Dari 15 sampel yang diuji diketahui 9 sampel mengandung alkohol dengan konsentrasi terbesar, yaitu 1,569\% v/v pada sampel D. Ditemukannya kandungan alkohol pada sampel bisa disebabkan karena limit deteksi alat yang digunakan untuk menganalisis alkohol berbeda-beda dan dapat dimungkinkan pula bahwa limit deteksi alat yang digunakan oleh produsen obat untuk menganalisis alkohol tersebut di atas alat kromatografi gas yang digunakan pada penelitian ini.

Hal ini dapat dilihat dari rentang konsentrasi alkohol yang ditemukan pada sampel, yang berada dalam rentang sangat kecil, yaitu 0,045\%-1,569\%. Makin kecil limit deteksi alat (LoD), akan makin baik untuk analisis suatu senyawa yang konsentrasinya kecil pula.

Peraturan BPOM menyebutkan bahwa untuk pengujian suatu produk akhir harus dilakukan oleh laboratorium terakreditasi, baik di dalam, maupun luar negeri atau laboratorium pemerintah. Hal ini menunjukkan bahwa sangat memungkinkan bila diperoleh hasil analisis alkohol yang berbeda-beda dalam sampel antar laboratorium.

Mengacu pada Fatwa MUI Tahun 2018 tentang penggunaan alkohol/etanol untuk bahan obat, ada beberapa syarat dibolehkannya penggunaan alkohol bukan khamr dalam obat, yaitu tidak ada penyalahgunaan dan tidak digunakan secara sengaja untuk membuat mabuk. Konsentrasi alkohol dalam darah atau Blood Alcohol Concentration (BAC) sebesar $1,80 \mathrm{~g} / \mathrm{L}$ dapat membuat efek mabuk (Neo et al., 2017).

Pada anak-anak dengan kondisi berat badan $20 \mathrm{~kg}$, nilai BAC 1,80 g/L bisa didapatkan dengan meminum obat batuk pada satu kali dosis lebih dari $100 \mathrm{~mL}$ dengan kadar alkohol 8,65\%. Tentunya akan diperlukan banyak volume obat batuk untuk membuat seseorang mabuk, mengingat konsentrasi alkohol dalam obat yang ditemukan dipasaran paling besar 10\% (Rahem, 2018).

Kasus penyalahgunaan obat batuk untuk membuat efek mabuk sudah terjadi di masyarakat. Namun, efek mabuk bukan 
Analisis Kadar Alkohol dalam Obat Batuk Sirup dengan...

disebabkan oleh adanya kandungan alkohol dalam obat tersebut, melainkan karena adanya kandungan Dekstrometorfan (Masoara, 2017; Salim, et al., 2020).

Syarat lain dibolehkannya penggunaan alkohol bukan khamr dalam obat adalah bahwa obat yang mengandung alkohol tersebut harus digunakan sesuai dosis dan aman. Bila mengacu pada FDA, penggunaan konsentrasi maksimum alkohol dalam obat-obatan oral dibagi menjadi beberapa rentang usia (Neo et al., 2017).

Penggunaan obat yang mengandung alkohol perlu diwaspadai bila obat tersebut diberikan kepada anak-anak di bawah 6 tahun. Hal ini disebabkan karena bayi yang baru lahir, balita, maupun anakanak tidak mampu melakukan metabolisme alkohol sebaik orang dewasa sehingga memiliki resiko yang besar terhadap keracunan akut dan kronis terhadap alkohol (Zuccotti \& Fabiano, 2011).

Svirskis et al (2013) melaporkan temuan alkohol dalam obat cair di Selandia Baru mencapai konsentrasi 76\% v/ v. Namun, jika pengunaan obat tersebut sesuai aturan dan dosis, tidak akan menimbulkan efek keracunan akut.

Konsentrasi alkohol dalam darah adalah persentase jumlah alkohol dalam darah. Satuan yang digunakan untuk mengukurnya adalah persentase berat alkohol per volume darah (\% w/v) atau ekivalen dengan g/dL (Manela \& Hidayat, 2018). Konsentrasi alkohol dalam darah yang mengacu pada satu dosis sirup yang mengandung alkohol tidak boleh melebihi 0,125 g/L (Huzar \& Wodnicka, 2013; Neo et al., 2017).

Neo et al. (2017) menyatakan bahwa nilai BAC pada $1,80 \mathrm{~g} / \mathrm{L}$ dapat menyebabkan gangguan penglihatan, reaksi yang melemah, gangguan koordinasi, dan kelabilan emosi. Berat badan, volume dosis obat, dan konsentrasi alkohol dalam obat yang digunakan sangat mempengaruhi nilai BAC. Hasil penelitian menunjukkan bahwa pada anak berusia 6 tahun $(20 \mathrm{~kg}$ ) yang diberi dosis $1 x$ obat (mengandung alkohol 8,65\%) sebanyak $10 \mathrm{~mL}$ memiliki BAC sekitar 0,06 g/L (Huzar \& Wodnicka, 2013).

Sebelum suatu produk memiliki logo halal, seluruh dokumen bahan baku obat tersebut ditelusur asal-muasalnya. Bahkan, jika diperlukan, bahan baku tersebut dapat diuji di laboratorium.

Undang-Undang No. 33 tahun 2014 tentang Jaminan Produk halal (JPH) pada tanggal 17 Oktober 2019 menyatakan bahwa semua produk yang masuk, beredar, dan diperdagangkan di Indonesia harus memiliki sertifikat halal merupakan kabar baik bagi konsumen muslim.

Hal ini menggambarkan bahwa dalam Undang-Undang JPH ini negara memiliki peran dalam memberikan pelayanan, perlindungan, dan jaminan hukum mengenai kehalalan suatu produk kepada seluruh masyarakat Indonesia (Rasyid, 2015).

Mengonsumsi sesuatu yang halal dan thayyib merupakan suatu kewajiban bagi umat islam. Bahkan, akan makin baik apabila konsumen muslim memiliki pengetahuan tentang adanya penggunaan alkohol dalam obat batuk maupun obat batuk yang telah memiliki logo halal.

Berdasarkan penelitian Rahem (2019) dan Nayeem et al. (2021) diketahui bahwa obat batuk yang tidak mengandung alkohol dan memiliki logo halal pada kemasannya. Undang-Undang JPH ini diharapkan akan memberikan dampak yang positif baik bagi produsen maupun konsumen muslim.

\section{Metode Analisis Alkohol dalam Sampel}

Beberapa penelitian menunjukkan bahwa analisis alkohol menggunakan kromatografi gas memiliki sensitifitas dan limit deteksi yang lebih baik dibandingkan dengan metode lain. Batista dan Filho (2020) melaporkan bahwa metode semua responden muslim lebih memilih 
Analisis Kadar Alkohol dalam Obat Batuk Sirup dengan...

\begin{tabular}{lll}
\hline headspace dan gas kromatografi & kurva standar alkohol memiliki \\
multidimensional Heart-cut yang & $\begin{array}{l}\text { persamaan } \mathrm{Y}=24,6575 \mathrm{X}-3086,7072 \\
\text { dengan R2 sebesar 0,999. Nilai R2 yang }\end{array}$ \\
digabungkan dengan spektroskopi massa & $\begin{array}{l}\text { semakin mendekati } 1 \text { menggambarkan } \\
\text { (HS-MDGC/MS) mampu mendeteksi }\end{array}$ \\
alkohol pada LoQ 0,06\% (v/v) dengan & $\begin{array}{l}\text { ketelitian pengerjaan analisis suatu } \\
\text { metode. }\end{array}$ \\
rentang akurasi $96,71 \%$ sampai $101,38 \%$. & Dari 15 sampel yang dianalisis, 9 \\
Pengembangan metode analisis & sampel terdeteksi mengandung alkohol \\
alkohol dalam obat sirup terus & dengan konsentrasi terbesar,yaitu 1,569\% \\
dikembangkan agar menghasilkan data & v/v dan 0,503\% b/b. Terdeteksinya alkohol \\
analisis yang akurat dan memiliki batas & dalam sampel obat batuk sirup dapat \\
deteksi sekecil mungkin sehingga & dimungkinkan karena limit deteksi alat \\
menjamin keamanan obat tersebut. & yang digunakan dalam penelitian ini \\
Penelitian Selvan \& Priya (2015) & berbeda dengan alat yang digunakan oleh \\
menyatakan bahwa metode kromatografi & produsen obat. \\
gas yang digunakan mampu mendeteksi
\end{tabular}

alkohol pada obat Kumaryasava dan Mustakarista sebesar 0,011-0,025\% v/v.

Metode spektrofotometri juga dapat digunakan untuk analisis alkohol. Jika dibandingkan dengan metode kromatografi gas, metode ini memiliki sensitifitas yang lebih rendah dalam menganalisis alkohol.

Dalam metode spektrofotometri digunakan suatu reagen/pereaksi yang nantinya akan menghasilkan spektrum warna karena hasil reaksi antara alkohol dengan reagen tersebut. Salah satunya dilaporkan oleh Sriariyanun et al. (2019) yang pada hasil penelitiannya mampu mendeteksi konsentrasi alkohol menggunakan reagen dikromat dalam sampel sebesar $0,8 \%$ sampai $7 \%$.

Analisis alkohol dengan metode titrasi juga dapat digunakan dengan baik pada pengamatan menggunakan mata telanjang atau menggunakan alat titrasi. Kudale et al. (2016) melaporkan bahwa analisis alkohol menggunakan alat titrasi dengan metode modifikasi oksidasi-difusi (dikromat) mampu membaca alkohol dengan rentang $2-40 \%$ v/v. Kelebihan metode ini adalah mudah, biaya preparasi sampel murah, dan instrument yang digunakan tidak terlalu mahal.

\section{PENUTUP}

\section{Kesimpulan}

Hasil penelitian menunjukkan bahwa

\section{Saran}

Diperlukannya keseragaman standar nilai batas deteksi (LoD) alat kromatografi gas untuk menganalisis alkohol dalam sampel pada semua laboratorium terakreditasi.

\section{DAFTAR PUSTAKA}

Astuti, N. P. W., Suaniti, N. M., \& Mustika, I. G. (2018). Validasi Metode dalam Penentuan Kadar Etanol Pada Arak Menggunakan Kromatografi Gas Detektor Ionisasi Nyala. Jurnal Kimia, 11(2), 128. https://doi.org/10.24843/ JCHEM.2018.V12.I02.P06

Huzar, E., \& Wodnicka, A. (2013). Determination Of Ethanol Content In Medicated Syrups by Static Headspace Gas Chromatography. Acta Poloniae Pharmaceutica - Drug Research, 70(1), 41-49. https://ptfarm.pl/ pub/File/Acta_Poloniae/ 2013/1/041.pdf

Kudale, A., Mulani, K., Toche, R., Borhade, S., Daundkar, B., \& More, B. (2016). Determination of Ethanol Content in Medicated Syrups: A Comparison among Distillation, Titration and GC Methods. Chemical Science Transactions, 5(1), 248-252. https://doi.org/10.7598/ cst2016.1180

Manela, C., \& Hidayat, T. (2018). Korelasi Kadar Alkohol dengan Derajat Luka 
Dalam Hal Pembuatan Visum Et Repertum pada Pasien Kecelakaan Lalu Lintas Rumah Sakit M. Djamil Padang. Jurnal Kesehatan Andalas, 7(3), 370-374. https://doi.org/10.25077/ jka.v7i3.888

Masoara, S. Y. (2017). Tinjauan Yuridis Terhadap Penyalahgunaan Komix Menurut Undang-Undang Nomor 35 Tahun 2009 Tentang Narkotika1 I Course Hero. Lex Crimen, 6(9), 34-41. https://www.coursehero.com/file/ 88992679/komixpdf/

Nayeem, A. R., Camara, I., Deep, T. A., Zalil, M. A., Ladi, M., \& Akter, M. F. (2021). Muslim Patients Attitude an Alcohol Content in Cough Medicine: An Analysis in Islamic Perspective. International Journal of Education and Knowledge Management, 4(1), 1-1o. https://doi.org/10.37227/IJEKM-202004-78

Neo, M. S., Gupta, S. M., Khan, T. M., \& Gupta, M. (2017). Quantification of Ethanol Content in Traditional Herbal Cough Syrups. Pharmacognosy Journal, 9(6), 821-827. https://doi.org/10.5530/ pj.2017.6.128

Rahem, A. (2018). Identifikasi Kandungan Alkohol dalam Obat di Apotik Melalui Pengamatan pada Kemasan Sekunder. Journal of Halal Product and Research, 1(2), 44-49.

Rahem, A. (2019). Sikap Pasien Terhadap Konten Alkohol dan Kehalalan Pada Obat Batuk. Journal of Halal Product and Research, 2(2), 106-113. https://ejournal.unair.ac.id/JHPR/article/ download/17009/9181

Rasyid, M. H. (2015). Peranan UndangUndang Jaminan Produk Halal dalam Menjamin Kehalalan Makanan dan Minuman. Jurnal Syariah 3.

Riyanto. (2014). Validasi dan verifikasi metode uji. Deepublish.
Salim, A., Maryati, T., \& Wirawan, I. G. M. A. S. (2020). Penyalahgunaan Obat Batuk Komix sebagai Fenomena Perilaku Penyimpangan Sosial di Kalangan Remaja Desa Sapeken, Sapeken, Sumenep dan Potensinya Sebagai Sumber Belajar Sosiologi di SMA. Jurnal Pendidikan Sosiologi Undiksha, 2(1), 73. https://doi.org/ 10.23887/JPSU.V2I1.28051

Selvan, P., \& Priya, E. S. (2015). Determination of ethanol content in ayurvedic formulations kumaryasava and mustakarista by gas chromatography. Indian Journal of Pharmaceutical Sciences, 77(1), 120-125. https://doi.org/10.4103/0250474X.151600

Sriariyanun, M., Mutrakulcharoen, P., Tepaamorndech, S., Cheenkachorn, K., \& Rattanaporn, K. (2019). A Rapid Spectrophotometric Method for Quantitative Determination of Ethanol in Fermentation Products. Oriental Journal of Chemistry, 35(2), 744-750. https://doi.org/10.13005/OJC/350234

Svirskis, D., Toh, M., \& Ram, S. (2013). The use of ethanol in paediatric formulations in New Zealand. European Journal of Pediatrics, 172(7), 919-926. https://doi.org/10.1007/ s00431-013-1972-0

United States Pharmacopeia. (2016). United States Pharmacopeia and National Formulary: USP 40 - NF 35. https:// www.uspnf.com/official-text/ proposal-statuscommentary/usp-40nf-35

Zuccotti, G. V., \& Fabiano, V. (2011). Safety issues with ethanol as an excipient in drugs intended for pediatric use. Expert Opinion on Drug Safety, 10(4), 499-502. https://doi.org/ 10.1517/14740338.2011.565328 